\title{
Neonatal Complications of Teenage Pregnancies: Prospective Study About 209 Cases in Senegal
}

\author{
Modou Gueye, Djibril Boiro, Amadou Sow*, Yaay J Dieng, Dieynaba F Cisse, \\ Aliou Abdoulaye Ndongo, Seynabou Senghor, Papa Moctar Faye, Ousmane Ndiaye \\ Department of Pediatrics, Cheikh Anta Diop University, Dakar, Senegal
}

Email address:

amadousoow@hotmail.com(A. Sow)

${ }^{*}$ Corresponding author

\section{To cite this article:}

Modou Gueye, Djibril Boiro, Amadou Sow, Yaay J Dieng, Dieynaba F Cisse, Aliou Abdoulaye Ndongo, Seynabou Senghor, Papa Moctar Faye, Ousmane Ndiaye. Neonatal Complications of Teenage Pregnancies: Prospective Study About 209 Cases in Senegal. American Journal of Pediatrics. Vol. 6, No. 4, 2020, pp. 504-507. doi: 10.11648/j.ajp.20200604.29

Received: November 25, 2020; Accepted: December 4, 2020; Published: December 16, 2020

\begin{abstract}
Summary: Early pregnancy is associated with a high risk of maternal and neonatal complications with significant neonatal morbidity and mortality, especially in developing countries. The objective was to assess morbidity and analyze the causes of neonatal mortality linked to these early pregnancies. Methodology: This was a prospective and descriptive study that took place from August 1, 2016 to January 31, 2017 in a hospital in Dakar. Included were newborns born to mothers aged 19 and under who gave birth in the maternity hospital. Results: 209 parturient were collected out of a total of 2073 parturient (10.08\%). The average age was 17.59 years. Thinness was noted in $7.3 \%$ and overweight in $19 \%$. Pregnancy was poorly followed in $32.1 \%$. The most common obstetric complications were the threat of premature delivery, premature rupture of membranes (PRM), arterial hypertension and preeclampsia. The indications for Caesarean sections were dominated by pelvic abnormalities $(28.4 \%)$ and PRM (11.4\%). The most common neonatal complications were prematurity $39.1 \%$, respiratory distress $12.72 \%$, maternal-fetal infections $12.27 \%$ and perinatal asphyxia $8.18 \%$. Mortality was $8.2 \%$. The number of prenatal consultation less than 4 was significantly associated with neonatal deaths. Conclusion: Teenage pregnancy is the source of many complications, especially in newborns. It is necessary to conduct communications campaigns in order to stem them.
\end{abstract}

Keywords: Adolescent Girl, Pregnancy, Mortality, Neonatal, Senegal

\section{Introduction}

Adolescent pregnancy is defined as pregnancy occurring in a girl aged 10-19 years [1]. The occurrence of an early pregnancy constitutes a difficult physical as well as a psychological test for the mother, and it is also associated with a high risk of neonatal complications such as low birth weight, prematurity [2-5], Foeto-pelvic disproportion [6, 7] and perinatal death $[3,8,9]$. Neonatal morbidity and mortality remains fairly high, especially in developing countries, despite the many actions taken to reduce it [10]. In Senegal, neonatal mortality today constitutes the largest share of deaths among children under 5 years old. [11] The objective of this work was to assess neonatal morbidity and to analyze the factors associated with mortality. of these early pregnancies.

\section{Methodology}

This was a prospective, descriptive and analytical study that took place from August 1, 2016 to January 31, 2017. Our study took place in the Maternity and Pediatrics departments of the Abass Ndao Hospital Center in Dakar, which is a level III public health establishment on the Senegalese health pyramid with an average of 5,000 deliveries per year. Included were newborns born to mothers aged 19 and under who gave birth in the maternity hospital. WHO considers adolescence to be the period of human growth and development between childhood and adulthood, between the ages of 10 and 19 . The parameters studied were sociodemographic (the geographical origin was classified into three zones: an urban zone, a peri-urban zone and a rural zone), The first-time mother is a woman who gives birth for 
the first time. The multipara is a woman who has had several deliveries, the mode of delivery). The neonatal data related to perinatal asphyxia which was retained if the APGAR score was less than or equal to 5 at the 5 th minute. The birth weight (low if weight $<2500 \mathrm{~g}$ and macrosome if weight $\geq 4000 \mathrm{~g}$ ). Prematurity is defined by any live birth occurring before the 37 th week of amenorrhea. Statistical analysis was performed with SPSS version 17.0 software and Excel 2010. Very great prematurity or Extremely premature $<28$ weeks). Statistical analysis was performed with SPSS version 17.0 software and Excel 2010. Very great prematurity or Extremely premature $<28$ weeks). Statistical analysis was performed with SPSS version 17.0 software and Excel 2010.

\section{Results}

During the study period, 209 parturients aged 14 to 19 were collected out of a total of 2,073 parturients, or $10.08 \%$. The mean age was 17.59 years [14-19 years] and the standard deviation was 1.265 . They were married in $70.7 \%$ of cases (140) and single in $29.3 \%$ of cases (58). The mean pregnancy was 1.16 [range 1-4] with a standard deviation of 0.419 . According to the BMI we noted thinness in $7.3 \%$ (12) and overweight in $19 \%$ (31). Pregnancy was well followed in 67.9\% (142 cases) and poorly followed in $32.1 \%$ (67 cases). Obstetric complications are summarized in Table 1. The pelvis was immature or abnormal in $23.2 \%$ (48). Delivery was done by cesarean section in $27.3 \%(57)$. The most common indications for Caesarean section were $28.4 \%$ pelvic abnormalities (25) (Table 2). The newborns had exclusive breastfeeding 35\% (80), mixed breastfeeding 38.8\% (47), and artificial breastfeeding $4.1 \%$. The neonatal complications were: prematurity in $34.1 \%$ (76), intrauterine growth retardation $20.3 \%$ (42), respiratory distress $13.4 \%$ (28) early neonatal infections $14 \%$ (27) (Table 3). Late neonatal infections were found in $22.5 \%$ (9). Mortality was $8.2 \%$, or 18 deaths out of 220 newborns. The deceased newborns were mainly from mothers over 18 years of age or having a BMI greater than $18 \mathrm{~kg} / \mathrm{m} 2$ or living in periurban areas and having performed less than 4 prenatal consultation. However, only this last parameter was statistically significant $(\mathrm{p}=0.007)$. (Table 4)

Table 1. Obstetric complications.

\begin{tabular}{lll}
\hline Pathology & Workforce (n) & Percent (\%) \\
\hline TPD & 54 & 26 \\
PRM & 47 & 22.6 \\
HBP & 24 & 11.7 \\
Preeclampsia & 22 & 10 \\
Anemia & 14 & 7 \\
STI & 13 & 6.22 \\
Haemorrhages & 8 & 5.4 \\
Urinary tract infections & 7 & 4.1 \\
Diabetes & 5 & 2.4 \\
Malaria & 3 & 1.5 \\
\hline \multirow{2}{*}{ TPD=Threatened premature delivery, PRM=Premature rupture of } \\
membranes, HBP=High blood pressure, STI=Sexually transmitted infection.
\end{tabular}

Table 2. Distribution according to the indication for cesarean section.

\begin{tabular}{llll}
\hline & Indication & Effective & (\%) \\
\hline \multirow{4}{*}{ Kindergarten } & Pelvic abnormality & 25 & 28.4 \\
& Failure to engage & 10 & 11.4 \\
& RPM & 10 & 11.4 \\
& Feto-pelvic disproportion & 5 & 5.7 \\
& Seat presentation & 4 & 4.5 \\
& Uterus scarring & 3 & 3.4 \\
& Preeclampsia & 16 & 18.2 \\
& Metrorrhagia & 2 & 2.2 \\
& AFD & 7 & 8 \\
& Macrosomia & 5 & 5.7 \\
& Cord procidence & 1 & 1.1 \\
\hline
\end{tabular}

$\mathrm{PRM}=$ Premature rupture of membranes, $\mathrm{AFD}=$ Acute fetal distress.

Table 3. Neonatal complications.

\begin{tabular}{lll}
\hline Neonatal complications & Effective & Percent (\%) \\
\hline Prematurity & 80 & 39.1 \\
Respiratory distress & 28 & 12.72 \\
Maternal-fetal infection & 27 & 12.27 \\
Perinatal asphyxia & 18 & 8.18 \\
Acquired neonatal infection & 9 & 4 \\
\hline
\end{tabular}

Table 4. Maternal factors associated with neonatal deaths.

\begin{tabular}{|c|c|c|c|c|c|c|}
\hline & & \multicolumn{4}{|c|}{ Neonatal death } & \multirow{3}{*}{ P Value } \\
\hline & & YES & & NO & & \\
\hline & & Effective & $\%$ & Effective & $\%$ & \\
\hline \multirow{2}{*}{ Maternal age } & $<18$ years & 7 & 9 & 71 & 91 & \multirow{2}{*}{0.992} \\
\hline & $\geq 18$ years & 11 & 9 & 111 & 91 & \\
\hline \multirow{2}{*}{ BMI } & $<18$ & 1 & 3.1 & 5 & 83.3 & \multirow{2}{*}{0.549} \\
\hline & $\geq 18$ & 14 & 9.3 & 137 & 90.7 & \\
\hline \multirow{3}{*}{ Geographic origin } & urban & 3 & 3.1 & 95 & 96.9 & \multirow{3}{*}{0.128} \\
\hline & peri-urban & 14 & 20 & 56 & 80 & \\
\hline & Rural & 1 & 3.6 & 27 & 96.4 & \\
\hline \multirow{2}{*}{ Number of PC } & $<4$ & 16 & 13.6 & 102 & 86.4 & \multirow{2}{*}{0.007} \\
\hline & $\geq 4$ & 2 & 2.5 & 79 & 97.5 & \\
\hline
\end{tabular}

BMI=Body mass index, $\mathrm{PC}=$ Prenatal consultation.

\section{Discussion}

The prevalence of teenage pregnancy was $10 \%$ in our study. Globally, pregnancy among adolescents aged 15-19 was estimated at $11 \%$ and occurred more $(90 \%)$ in lowincome countries [12]. Higher prevalences were reported in a meta-analysis across regions of the African continent. Indeed, 
the overall prevalence in Africa was $18.8 \%$ and $19.3 \%$ in the sub-Saharan region. It was highest in East Africa (21.5\%) and lowest in North Africa (9.2\%) [13]. Other authors in Cameroon have reported lower prevalence (8.2\%) [14]. Despite all the efforts made by our governments in terms of education, schooling, keeping girls in school and contraception, teenage pregnancies remain a scourge in our developing countries. A third of these pregnant adolescents were poorly monitored $(32.1 \%)$. This rate is different from what is found in the overall population of pregnant women in Senegal. Indeed, of the overall population of pregnant women, 54\% received at least four visits, and for $61 \%$, the visit took place before the first four months of pregnancy as recommended [15]. Insufficient follow-up could be explained by denial of pregnancy, lack of experience, or lack of knowledge about the first signs of pregnancy, or poverty. In Ethiopia, $12 \%$ of pregnant adolescents were not followed up against $4.5 \%$ of pregnant adults. [16] Regarding obstetric morbidity, the most common complications were the threat of premature delivery $(26 \%)$, premature rupture of membranes $(22.6 \%)$ and arterial hypertension (11.7\%). While in 2013, on a similar retrospective work carried out in Senegal, the authors found other complications: malaria $40.2 \%$, anemia with $25 \%$, urinary tract infection and hypertension $13 \%$ [10]. Other complications have been described: eclampsia, puerperal endometritis, and systemic infections [1]. In addition, a Malian study found $48.4 \%$ of malaria [17]. Infectious complications have been greatly reduced, especially malaria. This is due to the important efforts that have been made within the framework of the national program to fight against malaria. The anomalies of the pelvis found in particular immature pelvis can be explained by the young age of the parturients. Neonatal complications were dominated by prematurity, low birth weight, respiratory distress, and early neonatal infections. By comparing adolescent girls with an adult population, Kassa et al found a greater risk of prematurity and low weight in pregnant adolescents [16]. Similar results have been described in the work of Althabe et al. [18]. Other authors have described a greater risk of asphyxiation in newborns born to adolescents. [14] Mortality was $8.2 \%$, the deceased newborns were mainly from mothers over 18 years of age or having a BMI greater than $18 \mathrm{~kg} / \mathrm{m} 2$ or living in peri-urban area and having performed less than 4 antenatal consultations. However, only this last parameter was statistically associated with mortality. Studies comparing neonatal mortality between an adult population and that of adolescents have all demonstrated its association with teenage pregnancy $[14,18]$. However, in some Asian regions there was no difference between adolescent girls and adults [18].

\section{Conclusion}

Teenage pregnancy is a real problem for both mother and newborn because of the serious complications it causes. In our context, mortality is mainly linked to poor quality of antenatal consultations. Awareness and education campaigns at all levels on teenage pregnancies could help to stem this scourge.

\section{References}

[1] Ganchimeg T, Ota E, Morisaki N, Laopaiboon M, Lumbiganon P, Zhang J, and al. On behalf of the WHO Multicountry Survey on Maternal Newborn Health Research Network. Pregnancy and childbirth outcomes among adolescent mothers: a World Health Organization multicountry study. BJOG 2014; 121 (Suppl. 1): 40-48.

[2] Chen CW, Tsai CY, Sung FC, Lee YY, Lu TH, Li CY, et al. Adverse birth outcomes among pregnancies of teen mothers: age-speci fi c analysis of national data in Taiwan. Child Care Health Dev 2010; 36: 232-40.

[3] Chen XK, Wen SW, Fleming N, Demissie K, Rhoads GG, Walker M. Teenage pregnancy and adverse birth outcomes: a large population based retrospective cohort study. Int J Epidemiol 2007; 36: 368-73.

[4] Conde-Agudelo A, Belizan JM, Lammers C. Maternal perinatal morbidity and mortality associated with adolescent pregnancy in Latin America: cross-sectional study. Am J Obstet Gynecol 2005; 192: 342-9.

[5] de Vienne CM, Creveuil C, Dreyfus M. Does young maternal age increase the risk of adverse obstetric, fetal and neonatal outcomes: a cohort study. Eur J Obstet Gynecol Reprod Biol 2009; 147: 151-6.

[6] Harrison K, Rossiter C, Chong H. Relations between maternal height, fetal birth weight and cephalopelvic disproportion suggest that young Nigerian primigravidae grow during pregnancy. Br J Obstet Gynaecol 1985; 92 (Suppl. 5): 40-8.

[7] Ganchimeg T, Mori R, Ota E, Koyanagi A, Gilmour S, Shibuya $\mathrm{K}$, et al. Maternal and perinatal outcomes among nulliparous adolescents in low- and middle-income countries: a multi-country study. BJOG 2013; 120: 1622-33.

[8] Mukhopadhyay P, Chaudhuri RN, Paul B. Hospital-based perinatal outcomes and complications in teenage pregnancy in India. J Health Popul Nutr 2010; 28: 494-500.

[9] World Health Organization. Pregnant Adolescents: Bringing a Promise of Hope to the World. WHO 2007.28p. ISBN 97892 4259378 .

[10] Djiba D. Morbidity mortality of newborns to adolescent mothers. Medical thesis. UCAD Senegal; 2013, 104p.

[11] UNICEF. Child survival and development. Unicef Senegal June 2017.www.unicef.org/senegal/french/pdf.

[12] World Health Organization (WHO). WHO Guidelines on Preventing Early Pregnancy and Poor Reproductive Outcome Among Adolescents in Developing Countries. Geneva: WHO; 2011.

[13] Getachew Mullu Kassa, AO Arowojolu, AA Odukogbe and al. Prevalence and determinants of adolescent pregnancy in Africa: a systematic review and Meta-analysis. Reproductive Health (2018) 15: 195.

[14] Rita F. Tamambang, Tsi Njim, Albertine E. Njie, Lawrence Mbuagbaw, Agnès Mafuta, Mesack Tchana and Simeon-Pierre Choukem. Adolescent deliveries in urban Cameroon: a retrospective analysis of the prevalence, 6-year trend and adverse outcomes. BMC Res Notes (2018) 11: 469. 
[15] National Agency for Demography and Statistics. Fourth phase / 2016 Demographic and Health Survey (EDS-continuous).

[16] Kassa GM, Arowojolu AO, Odukogbe AA, Yalew AW Adverse neonatal outcomes of adolescent pregnancy in Northwest Ethiopia. PLoS ONE 14 (6): e0218259. https://doi.org/10.1371/journal.pone.0218259 (2019).
[17] Traoré F. Consequences of Early Pregnancies in Bamako urban areas. Medical thesis. Mali; 2001-2002, 104p.

[18] Fernando Althabe, Janet L Moore, Luz Gibbons and al. Adverse maternal and perinatal outcomes in adolescent pregnancies: The Global Network's Maternal Newborn Health Registry study. Reproductive Health 201512 (Suppl 2): S8. 